\title{
Múltiplas linguagens, mídias e letramentos em ação
}

\author{
Mariana Lettieri Ferreira ${ }^{\mathrm{i}}$ \\ Lucila Pesce ${ }^{\text {ii }}$
}

\section{RESENHA}

ROJO, Roxane; MOURA, Eduardo. Letramentos, mídias e linguagens. São Paulo: Parábola Editorial, 2019.

O livro Letramentos, mídias e linguagens, publicado em 2019, é o mais recente lançamento dos pesquisadores Roxane Rojo e Eduardo Moura. Roxane Rojo é uma pesquisadora livre docente do Departamento de Linguística Aplicada do Instituto de Estudos da Linguagem da UNICAMP. Seus trabalhos enfocam, em sua maioria, os (multi)letramentos e práticas escolares que possam promovê-los. Autora de diversos livros, dentre os quais destacamos: Letramentos múltiplos, escola e inclusão social (2009), Multiletramentos na escola (2012), organizado em parceria com Eduardo Moura,Escol@ conectada: os multiletramentos e as TICs (2013), organizada pela autora, e Hipermodernidade, multiletramentos e gêneros discursivos (2015), escrito em coautoria com Jacqueline P. Barbosa (IEL/Unicamp).

O outro pesquisador, Eduardo Moura, é formado em Arte e Cultura Fotográfica, pelo SENAC, licenciado em Letras, pela PUC-SP, doutor em Linguística Aplicada, pela UNICAMP, sob orientação da Profa. Dra. Roxane Rojo e pós-doutorando em Linguística Aplicada, pela USP. Atua na formação docente, especialmente no tocante aos novos e multiletramentos. Organizou e publicou um livro com Rojo em 2012 (Multiletramentos na escola) e agora juntos novamente publicaram, em 2019, o livro Letramentos, mídias e linguagens.

\footnotetext{
${ }^{i}$ Mestranda em Educação no PPG da Universidade Federal de São Paulo (UNIFESP), especialista em "Práticas Reflexivas e Ensino-Aprendizagem de Inglês na Escola Pública" (PUC-SP), bacharel e licenciada em Letras - Inglês e Português (USP), pedagoga (Uninove). Professora de Ensino Fundamental II e Médio - Inglês na Prefeitura do Município de São Paulo (SME-SP).

ORCID: https://orcid.org/0000-0002-9024-736X | lferreira.mariana@gmail.com

ii Doutora em educação (PUC-SP), com pós-doutorado em filosofia e história da Educação (Unicamp). Professora Associada do Depto. de Educação e credenciada no PPGE da Universidade Federal de São Paulo.

ORCID: http://orcid.org/0000-0002-2562-2012 | lucila.pesce@unifesp.br
} 
Essa obra já antecipa, mediante título simples e direto, o que encontraremos no livro desses pesquisadores, que apresentam, de maneira didática e multimodal, o que são letramentos, mídias e as diferentes linguagens: imagem estática, imagem dinâmica, música e verbo.

O livro se divide em duas partes: uma com os dois primeiros capítulos da obra, que se propõem a apresentar o referencial teórico dos autores, no que diz respeito aos letramentos e às mídias; e a outra com os capítulos 3 a 6 , que buscam detalhar cada uma das linguagens e seus desdobramentos(“a imagem estática", "a imagem dinâmica”, "a música" e "o verbo"). É interessante observar que, no decorrer da obra, os autores optaram por um livro com diversos hiperlinks apresentados na forma de $Q R$ codes, de maneira a ilustrar o que está sendo discutido e apresentado, além de tornar a leitura mais dinâmica, fluida e multimodal.

No capítulo 1, ao tratar dos letramentos, os autores o subdividem em três partes, a saber: "letramentos da escrita e do impresso", "multiletramentos" e "novos (multi)letramentos". Chama-se a atenção para a flexibilidade do termo, que acompanha diversas mudanças e, de certa forma, os termos acabaram por demonstrar uma ampliação no conceito decorrente dos "avanços" do mundo. Na primeira parte do capítulo, é feita uma espécie de linha do tempo, que se inicia nos anos de 1980, quando o termo foi introduzido nos trabalhos de pesquisadores brasileiros. Também é feita a distinção entre o termo letramento e alfabetismo. Para isso, os autores fazem referência aos trabalhos de Mary Kato, Magda Soares, Ângela Kleiman e Brian Street.

A tônica dessa primeira parte do capítulo é a defesa de a "escola se tornar uma agência de democratização dos letramentos" (ROJO; MOURA, 2019, p. 17), de modo que os alunos tenham acesso a diversas práticas e eventos de letramento. Inclusive, Rojo advoga, em todas as suas publicações citadas no início desta resenha, especialmente no que diz respeito a reconhecimento e inclusão por parte da escola, letramentos considerados desvalorizados/marginais.

No segundo momento do capítulo, os autores buscam definir os multiletramentos, com base no quadro teórico de referência do Grupo de Nova Londres ${ }^{1}$ (GNL) (1996), que reconheceu os multiletramentos a partir das múltiplas modalidades e da multiplicidade de culturas. Eles apresentam de maneira mais breve os multiletramentos, segundo o GNL, inclusive porque este conceito já havia sido 
apresentado e discutido mais especificamente nos livros de 2012 e 2013. Ainda nessa seção, as ideias de Kress complementam as explicações, uma vez que, para o autor, "a linguagem verbal sozinha não pode mais dar conta das mensagens construídas de maneira multimodal.” (ROJO; MOURA, 2019, p. 24). Dessa forma, já podemos perceber um dos intuitos do livro de apresentar as diversas linguagens nos capítulos subsequentes, já que converge com o que é apresentado a partir de Kress.

Finalmente, na última parte do capítulo, são anunciados os novos (multi)letramentos, a partir das teorias de Lankshear e Knobel. O adjetivo "novo", para esses autores, apontava em direção às mudanças que as Tecnologias Digitais de Informação e Comunicação (doravante TDIC) provocaram nos letramentos. Assim, o foco dessa última parte do capítulo é justamente o novo ethos, a nova mentalidade que surgiu, com o advento da Web 2.0. De acordo com Rojo e Moura, "os novos letramentos são mais participativos, colaborativos, distribuídos; ou seja, menos individualizados, autorados, dependem menos de licenças de publicação" (ROJO; MOURA, 2019, p. 26). Por isso, há uma grande ênfase no surgimento da cultura remix e da hibridização, que será parte fundamental nos capítulos subsequentes.

Conforme mencionado anteriormente, os autores desejavam que o livro fosse hipertextual e hipermidiático. Logo, no decorrer do livro, através de $Q R$ codes, há diversas referências de websites e vídeos, de modo a complementar e a ilustrar o que está sendo discutido. No caso desse primeiro capítulo, os autores encerram com uma referência ao ciberativista Aaron Swartz e um vídeo que apresenta a trajetória do garoto, que lutava pelo livre acesso ao conhecimento e à informação. Essa foi uma boa escolha dos autores para demonstrar as "premissas" dos novos (multi)letramentos, nos quais se espera a colaboração e a participação mais ativa dos partícipes.

O segundo capítulo ocupou-se de definir mídia e está dividido em quatro seções: "mídia como meio de comunicação"; "mídia e modo"; "mídias, multimídia, hipermídia"; e "um mundo transmídia". O intuito dos pesquisadores é evidenciar o que eles entendem por mídia e como as novas TDIC "vêm alterar a relação entre as várias mídias" (ROJO; MOURA, 2019, p. 31). As ideias de Santaella (2003a, 2003b) estão muito presentes, não apenas nesse capítulo, mas também no decorrer da obra, uma vez que a autora ocupou-se de estudar a "cultura das mídias", que seria, portanto, "um momento em que o consumidor passa a ter alguma escolha, momento em que pode 
passar a montar suas próprias 'coleções', como diria García-Canclini (2008 [1998])"(ROJO; MOURA, 2019, p. 34).

Além disso, o conceito de Jenkins (2006), de cultura de convergência, também está muito presente nesse capítulo. Com base em Santaella (2007), são apresentadas as cinco "gerações tecnológicas". Na seção destinada a discorrer sobre mídia e modo, os autores apresentam o aporte teórico a ser utilizado. À vista disso, optou-se pelo termo multissemiose, ao invés de multimodalidade, conforme apresentado pelo GNL e Kress. Ao definir mídia, multimídia, hipermídia e metamídia, Rojo e Moura apresentam um breve estudo teórico conceitual, para que o leitor acompanhe as passagens que resultaram nos termos. Por fim, ao tratar de transmídia, além da definição, retomam-se as ideias de Jenkins (2006) acerca de cultura da convergência, que é a interação de novas e velhas mídias. Os autores preocupam-se em distinguir crossmedia e transmídia. Nesse momento, aparece a cultura de fãs, como parte integrante da rede de colaboração proporcionada a partir do advento da Web 2.0. Após a definição desses "conceitoschave", como os autores chamam, a segunda parte do livro procura se debruçar mais detalhadamente sobre cada tipo de linguagem.

Cabe, até mesmo, acrescentar que o livro como um todo é muito bem apresentado e diagramado, em especial a escolha de cores e fontes para o design. Outrossim, diversas imagens compõem os capítulos, auxiliando na construção dos significados de diferentes modos, que, em alguns momentos são capturas de um momento do hiperlink (por exemplo, no caso de um vídeo há a captura de uma cena), ou imagens de pinturas e fotografias. Tais imagens ilustram, com maestria, o que está sendo discutido, além de, no caso dos vídeos, aguçar a curiosidade do leitor. Também reafirma a escolha dos autores em tornar a produção multimodal.

No que se refere a esse processo estilístico, é possível traçar um paralelo entre o trabalho de diagramação e o diálogo com a formação de Moura e sua atuação. O autor possui formação em arte e cultura fotográfica, além de ter realizado seu estágio de doutoramento (2017-2018) na Pennsylvania State University, School of Visual Arts Arts \& Design Research Incubator (Penn State - ADRI), sob supervisão do Professor Doutor Eduardo Navas. Sua atuação na área de produção de materiais didáticos para o ensino de Língua Portuguesa e formação de professores para trabalharem com novos e multiletramentos evidencia-se na apresentação primorosa da obra em tela. 
Ao discorrer sobre a imagem estática, Rojo e Moura dividem o terceiro capítulo em quatro momentos mais "teóricos", conforme apresentado a seguir. No final, há uma seção intitulada "fazendo gênero". Essa seção aparece em todos os capítulos, a partir desse ponto, na qual os autores expõem algum gênero textual que dialoga com os conceitos apresentados, com vista a oferecer subsídios ao trabalho do professor que optar por trazê-los para a sala de aula. Vale ressaltar que em nenhum momento os autores propõem ao docente sequências de atividades ou sugestões. Essa obra é muito mais teórica, se comparada a que foi organizada por eles em 2012. Entretanto, durante a leitura, são apresentados diversos gêneros e novas práticas de letramento que vêm surgindo nos últimos tempos.

Portanto, na parte supracitada, os autores discorrem acerca: "das arquitetônicas e sistemas semióticos tipológicos e topológicos"; "dos três paradigmas da imagem estática: pré-fotográfico, fotográfico, pós-fotográfico"; "do pré-fotográfico à fotografia: a imagem ex machina"; e "do fotográfico ao pós-fotográfico: do tratamento digital das imagens".

$\mathrm{Na}$ seção "fazendo gênero", os autores comentam sobre o "Photoshop. Renderização e a estética IA", com base nos aportes teóricos do Círculo de Bakhtin, conforme desenvolvido por Faraco (2011), Santaella (2001; 2003; 2007; 2013), Santaella e Noth (2014 [1997]) e Lemke (2010 [1998]; 2012). A escolha de Rojo e Moura, ao construir os capítulos, é muito pertinente para o leitor, que acompanha o "desenvolvimento" de cada semiose, cronologicamente. No caso da imagem estática, há um percurso que vai desde a pintura, passando pela fotografia, até as imagens digitais compostas por pixels. Ao tratar do gênero, novamente há a referência à cultura do remix e são introduzidos diversos conceitos envolvidos nessas práticas. A leitura se torna fluida, tornando agradável a 'navegação' pelo capítulo e pelas diversas referências de vídeos, que complementam o quese discute na obra.

Nesse mesmo movimento, o capítulo quatro trata da imagem dinâmica e está subdivido em: "os três paradigmas da imagem dinâmica: pré-cinematográfico, cinematográfico e pós-cinematográfico"; "do pré-cinematográfico ao cinema: entre o espetáculo e a montagem"; “do cinematográfico ao pós-cinematográfico: a metamídia"; “fazendo gênero: fans vids e AMV - entre a cultura de fãs e a cultura otaku”. Valendose de teóricos como Santaella e Noth (2014 [1997]), os autores tecem novamente o 
capítulo com conceitos específicos, referências externas e teoria. Há nova retomada do remix e é apresentado o sampling, conceito que estará muito mais presente no quinto capítulo. Há, ademais, muita referência a técnicas de edição que a imagem dinâmica permite.

No quinto capítulo, que trata do som, a trajetória bem musical de referências e hiperlinks torna o percurso muito mais agradável e didático. Amparados em Wisnik e Navas, os autores exploram: "os três paradigmas do som: modal, tonal e pós-tonal (ou serial)"; “do modal para o tonal: perdendo o ritmo?”; "o pós-tonal: o serial ou a música eletroacústica"; e "fazendo gênero: sampling". São diversos os momentos que promovem a reflexão, em especial quando se apresenta uma breve discussão sobre direitos autorais e criatividade, antes de introduzir a ideia de sampling, a qual utiliza um trecho já existente de uma música para criar algo completamente novo.

Por último, no capítulo que encerra o livro, os autores tratam do verbo, mais especificamente, da linguagem verbal. Esse está dividido em: "os três paradigmas do texto: pré-tipográfico, tipográfico e pós-tipográfico"; “do pré-tipográfico à tipografia: a escrita e o impresso"; "o texto pós-tipográfico: hipertexto, hipermídia, metamídia”; e "fazendo gênero: reportagem multimídia". Novamente ancorados em Santaella e Noth (2014 [1997]), Rojo e Moura apresentam a linguagem "escrita" e retomam conceitos que já apareceram em outras obras de Rojo (2012; 2013), como o de "produsuário" e a questão da autoria presente na Web 2.0 e no conceito de multiletramentos e novos (multi)letramentos. Ao apresentar o gênero de reportagem hipermidiática, é interessante perceber as possibilidades que as TDIC trouxeram para o gênero reportagem, bem como as mudanças que o suporte digital contempla, diferentemente do impresso.

Percebe-se, dessa forma, que uma das contribuições do livro é reunir e exemplificar tantos conceitos que surgiram recentemente em uma obra que não se esgota em si mesma, mas, ao contrário, conduz o leitor a novos horizontes para a incorporação e a vivência de "letramentos, mídias e linguagens". Ao oferecer referências externas, a obra possibilita que o leitor aprofunde-se em um conceito mais específico e que possa procurar por mais referências e exemplos. Com isso, o livro é recomendado a todos aqueles que desejam saber mais sobre letramentos, mídias e linguagens. 


\section{Referências}

FARACO, Carlos Alberto. Aspectos do pensamento estético de Bakhtin e seus pares. Letras de Hoje. Porto Alegre, v. 46, n. 1, p.21-26, jan./mar, 2011.

LEMKE, Jay. "Metamedia literacy: Transforming Meanings and Media". In: REINKING, D.; MCKENNA, M.C.; LABBO, L.D.; KIEFFER, R.D. (orgs.). Handbook of Literacy and Technology: Transformation in a Post- Typographic World. Mahwah: Erlbaum, p. 283-302, 1998.

LEMKE, Jay. Tipologia, topologia, topografia: A semântica dos gêneros. Revista de Letras, n. 31, v. (1/2) jan./dez. Fortaleza: Imprensa Universitária da UFC, 2012.

LEMKE, Jay. "Multiplying Meanings: Visual and Verbal Semiotics in Scientific Texts". In: MARTIN, J. R.; VEEL, R. (orgs.). Reading Science: Critical and Functional Perspectives on Discourse of Science. New York: Routledge, p.87-113, 1998.

ROJO, Roxane. Letramentos múltiplos, escola e inclusão social. São Paulo: Parábola Editorial, 2009.

ROJO, Roxane. "Pedagogia dos multiletramentos: diversidade cultural e de linguagens na escola". In: ROJO, Roxane; MOURA, Eduardo. (orgs.). Multiletramentos na escola. São Paulo: Parábola Editorial, 2012.

ROJO, Roxane. (org.).Escol@ conectad@: os multiletramentos e as TICs. São Paulo: Parábola Editorial, 2013.

ROJO, Roxane; BARBOSA, Jacqueline. Hipermodernidade, multiletramentos e gêneros discursivos. São Paulo: Parábola, 2015.

ROJO, Roxane; MOURA, Eduardo. Letramentos, mídias e linguagens. São Paulo: Parábola Editorial, 2019.

SANTAELLA, Lucia. "A sintaxe como eixo da matriz sonora". In: Matrizes da linguagem e pensamento: sonora, visual, verbal. São Paulo: Iluminuras, pp.112-116, 2001.

SANTAELLA, Lucia. Culturas e artes do pós-humano: da cultura das mídias à cibercultura. São Paulo: Paulus, 2003a.

SANTAELLA, Lucia. Da cultura das mídias à cibercultura: o advento do pós-humano. Revista FAMECOS, n. 22, p. 23-32. Porto Alegre: RS. $2003 \mathrm{~b}$.

SANTAELLA, Lucia. Linguagens líquidas na era da mobilidade. São Paulo: Paulus, 2007.

SANTAELLA, Lucia. Comunicação ubíqua: repercussões na cultura e na educação. São Paulo: Paulus, 2013.

SANTAELLA, Lucia; NOTH, Winfried. Imagem: cognição, semiótica e mídia. São Paulo: Iluminuras, 2014 (1997). 
Recebido em: 14/01/2021

Aceito em: 29/01/2021

\footnotetext{
${ }^{1}$ Um grupo de pesquisadores que se reuniu na cidade homônima nos Estados Unidos para discutir os avanços em diversas áreas promovidos pela globalização e que resultou num manifesto que cunhou o termo multiletramentos.
} 